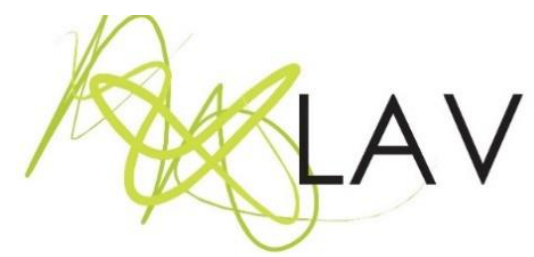

\title{
O lugar do relato autobiográfico no sistema formativo Cartografias de si
}

The place of the autobiographical account in the formative system Cartographies of themselves

\author{
Sumaya Mattari \\ Escola de Comunicações e Artes/USP
}

\begin{abstract}
Uma história de vida não é feita para ser arquivada ou guardada numa gaveta como coisa, mas existe para transformar a cidade onde ela floresceu.
\end{abstract}

(Ecléia Bosi, 2003).

\begin{abstract}
Resumo
O texto apresenta as bases do trabalho com as narrativas de vida no âmbito do sistema Cartografias de si, uma perspectiva metodológica de trabalho com educadores composta por uma série de proposições, meios, processos e procedimentos, cujo eixo é o denominado ato cartográfico. Trata-se de uma perspectiva metodológica que postula a integração entre as esferas da criação artística e pedagógica e privilegia o papel da experiência nos processos de aprendizagem de adultos. Entre os vários dispositivos utilizados no âmbito do sistema, o texto focaliza aquele que inaugura e aciona o processo formativo com os educadores: o relato autobiográfico.
\end{abstract}

Palavras-chave: formação de professores; arte/educação; cartografias, narrativas de vida, autobiografias.

\begin{abstract}
The text presents the basis of the work with the life narratives within the system Cartografias de si, a methodological perspective for working with educators, composed of a series of propositions, means, processes and procedures, whose axis is the so-called cartographic act. It is a methodological perspective that posits the integration between the spheres of artistic and pedagogical creation and privileges the role of experience in the processes of adult learning. Among the various devices used within the system, the text focuses on what inaugurates and activates the formative process with the educators: the autobiographical report.
\end{abstract}

Keywords: teacher training; art/education; cartographies, life narratives, autobiographies. 


\section{Introdução}

Há uma história oficial, aquela que está nos livros de história, cujas datas importantes todos, de alguma forma, temos conhecimento, mas há também muitas outras histórias que não cabem nos livros oficiais: as histórias de cada um, construídas ao longo de uma vida, nos embates do cotidiano, na relação com pessoas, nas pequenas alegrias, no enfrentamento de conflitos e dificuldades.

Necessitamos contar nossas histórias a alguém. O relato primordial é aquele que pode ser feito a outras pessoas, seja pela palavra falada, seja pela palavra escrita. Nossas histórias ganham relevância quando as relatamos. Através delas, o que vivemos ganha uma dimensão social, obtém testemunhas e faz com que outras pessoas ampliem sua experiência através da nossa palavra.

Recolher histórias de vida de educadores não é, pois, apenas o recolhimento de um testemunho pessoal, tampouco é uma tarefa movida por uma curiosidade científica. É um ato político, um modo de resistência, uma maneira de dar voz para uma classe bastante sofrida e desvalorizada, que, de outra forma, ficaria calada e permaneceria excluída da história.

Além da dimensão social e política, rememorar a própria história de formação, encontrando elos significativos entre as experiências, localizando pessoas e acontecimentos importantes, (re)descobrindo o sentido das escolhas feitas, entre outras coisas, têm enorme potencial pedagógico na formação docente; não à toa, há muitas pessoas trabalhando nesta perspectiva no Brasil e em várias outras partes do mundo.

A experiência de refletir sobre minhas experiências formativas mostrou-se, em si, um momento formativo. Circular por esses guardados de gavetas, como diz Iberê Camargo, inundou-me, não apenas de lembranças, mas também de sentidos, valores e significações. ${ }^{1}$

Quando começamos a trabalhar com a formação de professores, há mais de vinte anos, a história de vida já ocupava o centro do nosso trabalho. Os professores rememoravam, escreviam e compartilhavam com os colegas os seus "relatos autobiográficos". O material que emergia dessa experiência nutria tanto o trabalho do grupo quanto os percursos individuais que a partir dali se desenvolviam.

\footnotetext{
${ }^{1}$ Fragmento do relato autobiográfico de V., artista, professor e pesquisador, escrito em 2009, no âmbito da disciplina de pós-graduação Professores de arte: formação e prática educativa, do Programa de Pós-Graduação em Artes Visuais da ECA/USP.
} 
Com o tempo, fomos compreendendo que rememorar e narrar são dispositivos de produção da subjetividade dos professores e, por isso, precisam ser acompanhados de outros dispositivos que possibilitem que eles lancem seu olhar também para o tempo vindouro, sob pena de ficarem estacionados em épocas já vividas e não encontrarem significado no tempo presente, tampouco no futuro.

Revisitar estes momentos reabriu significados, me fez ver como as nossas experiências passadas precisam sempre ser revisitadas sob novos aspectos, estamos sempre mudando e é essencial se valer disso para se desenvolver, não ficar preso ao passado. ${ }^{2}$

A partir da colaboração de inúmeros grupos de estudantes e professores com os quais trabalhamos, fomos criando outros dispositivos e sistematizando o que hoje denominamos sistema formativo Cartografias de si, denominação inspirada nos estudos de Foucault - ele próprio um cartógrafo (DELEUZE, 2013, p. 53) - acerca das práticas em torno dos cuidados de si presentes na cultura greco-romana. ${ }^{3}$

\section{Cartografias de si e processos de subjetivação}

Segundo Foucault, o conhecer a si mesmo do mundo grego antigo, aos poucos, deu lugar ao cuidar de si mesmo, de tal modo que uma estética da existência voltada ao trabalho sobre si mesmo orientava a vida dos indivíduos: "as artes de si mesmo" (FOUCAULT, 2004, p. 144).

Os cuidados de si eram uma maneira do sujeito [...] se elaborar, se transformar e atingir um certo modo de ser (FOUCAULT, 2004, p. 265). Além do trabalho com o corpo, o trabalho com a mente, o espírito e a cultura, o trabalho sobre si mesmo se dava por meio de exercícios praticados e recomendados pelos estóicos. Tais exercícios envolviam, entre outras atividades, a leitura, a audição, o ensino e a escrita.

Tratavam-se de exercícios voltados para objetivos bem definidos: recolher-se em si, atingir a si mesmo, viver consigo mesmo, bastar-se a si mesmo, aproveitar e gozar de si

\footnotetext{
${ }^{2}$ Fragmento do relato autobiográfico de A., artista e educador, escrito em 2009, no âmbito da disciplina de pósgraduação Professores de arte: formação e prática educativa, do Programa de Pós-Graduação em Artes Visuais da ECA/USP.

3 O sistema formativo Cartografias de si foi construído e sistematizado e continua sendo reconstruído, especialmente no âmbito de nossas aulas nos cursos de graduação e de pós-graduação na Universidade de São Paulo. Na última década, trabalhamos com cerca de nove turmas de pós-graduação, quarenta e cinco turmas de graduação e oito turmas do curso de especialização. Tais situações, somadas, envolveram mais de 700 pessoas, além daquelas participantes dos cursos e oficinas que ministramos fora da Universidade, portanto, recolhermos mais de 700 narrativas autobiográficas ao longo deste período. As disciplinas e cursos que ministramos regularmente na Universidade são as seguintes: Arte, experiência e Educação, cartografias de si: percursos de formação e processos criativos de professores, do Programa de Pós-Graduação em Artes Visuais; Laboratório de experimentação e criação poético-pedagógicas, do curso de Especialização Arte na Educação, do Departamento de Música; o conjunto de disciplinas denominadas Metodologias do Ensino das Artes Visuais com Estágios Supervisionados (I, II, III e IV) e o projeto de extensão Vivências com a arte para jovens e adolescentes, ambos do Departamento de Artes Plásticas.
} 
mesmo (FOUCAULT, 2004, p. 149). O que propomos no processo formativo com professores, aproxima-se da ideia dos cuidados de si e da estetização da existência, tal qual explicada por Foucault.

O sistema Cartografias de si é uma perspectiva de trabalho com professores baseada na arte como processo de subjetivação, uma perspectiva composta por um conjunto de proposições, meios, processos e procedimentos teóricos, poéticos e didáticos denominados atos cartográficos, ou simplesmente cartografias, que nada mais são que diagramas de fluxos, mapas de trajeto, em sua maioria, de natureza verbo-visual, capazes de imprimir sentido temporal e topológico aos percursos formativos dos sujeitos participantes do processo. ${ }^{4}$

Ainda que possa parecer, não se trata de trabalho pautado no indivíduo como valor universal e globalizante, uma categoria inventada e institucionalizada na modernidade e supervalorizada na sociedade capitalista neoliberal. Esse é um sério risco que se corre quando se trabalha com a subjetividade no âmbito da formação de adultos, já que as ideias, os princípios, os métodos e as práticas que sustentam o neoliberalismo e ditam as regras da sociedade capitalista atual, estão absolutamente disseminados e fazem parte de todas as esferas da vida.

O individualismo - essa sofisticada elaboração ideológica particular ao Ocidente, mas que, não obstante, é projetada em outras sociedades e culturas como um dado universal da experiência humana (DAMATTA, 2000, p. 3) - deve ser enfaticamente excluído e jamais alimentado e incentivado em qualquer trabalho educativo.

Longe desta lógica individualista neoliberal, o sistema formativo Cartografias de si valoriza a individualização, uma experiência universal, destinada a ser culturalmente reconhecida, marcada, enfrentada ou levada em consideração por todas as sociedades humanas (DAMATTA, 2000, p. 3).

As experiências, os estudos, as conversas e os afetos em circulação, no decorrer do referido processo formativo vão estabelecendo uma ética coletiva de convívio no grupo, quando vai se estabelecendo a necessária distinção entre o indivíduo como realidade empírica e o estabelecimento deste como uma entidade social autônoma ou um valor social (DAMATTA, 2000, p. 3). Isso ocorre porque a ética pressupõe a ação refletida do indíviduo sobre si mesmo, e essa é uma dimensão da individualidade e não do individualismo.

${ }^{4}$ Informações detalhadas sobre o sistema Cartografias de si podem ser encontradas em Mattar (2017a, 2017b, 2017c). 
Na educação escolar, o trabalho com a esfera da subjetividade também oferece riscos. $\mathrm{O}$ sujeito da educação é o sujeito construído na modernidade - um sujeito universal. Assim, a escola que está aí está voltada para a lapidação do estudante para que sua essência se manifeste e ele se torne aquilo que já é. Há pouca margem para a construção de condutas singulares neste espaço. Se o individualismo opera em todas as esferas da vida como sendo algo natural, a educação facilmente toma para si a tarefa de preparar o estudante para se adequar a essa lógica perversa.

Isso significa que não é possível falarmos de cuidados de si na escola? Se considerarmos, com Foucault, o sujeito como produção histórica, obra inacabada e em constante construção, uma perspectiva aberta, criativa e construtiva, é possível afirmar a importância e propor práticas de si e do exercício da liberdade tanto na educação escolar quanto na formação de professores. Mas isso só é possível na perspectiva do sujeito como construção inacabada, sob pena de exacerbarmos o individualismo, o egoísmo e o narcisismo ditados pela sociedade neoliberal. Ou seja, se a escola compreendesse a educação como um importante processo de produção da subjetividade, as práticas pedagógicas não seriam guiadas por objetivos externos aos estudantes, tampouco deixariam espaço para práticas diretivas e conteudistas, infelizmente, ainda muito observadas.

Realizar estes exercícios fez com que eu saísse da minha zona de conforto de uma forma que dificilmente eu fazia - fui percebendo no decorrer do semestre o quanto eu me sabotava com esse comodismo -, eu resisti muito, mesmo sem saber direito o porquê. $A$ despeito da dificuldade, e talvez justamente por ela, o processo foi completamente essencial tanto para a minha formação como para a minha vida. Escrever inúmeras páginas com brainstorm sobre o que me fascinava, o que eu havia esquecido ou guardado, o que eu precisava deixar para trás e os caminhos que eu podia tomar, permitiu que eu enxergasse que não estava tão perdida quanto imaginava e fez com que eu recobrasse parte do ânimo que eu precisava. ${ }^{5}$

O fato é que só podemos cuidar dos outros quando somos capazes de cuidar de nós mesmos, destarte, considerar os estudantes como sujeitos inacabados pressupõe educadores capazes de cultivarem a si mesmos. De outro modo, não seria possível cuidarem dos estudantes e permitirem que sejam sujeitos de si e adquiram autonomia.

Desde que nos comprometamos com a formação de sujeitos que se percebam como sujeitos, mas não deixem de lembrar que fazem parte de uma sociedade, é possível

5 Trecho da reflexão final de I., estudante de licenciatura em Artes Visuais, escrita em 2017, no âmbito da disciplina de graduação Metodologia do Ensino das Artes Visuais I, da ECA/USP. 
desencadear processos educativos genuinamente comunitários e colaborativos, seja com professores, seja com estudantes, processos que sejam alicerçados em uma ética coletiva: devemos cuidar de nós para melhor cuidarmos dos outros e, juntos, repudiarmos a lógica neoliberal individualista e egoísta da sociedade atual.

Trata-se, pois, da ética percebida como "estética da existência" (FOUCAULT, 2004, p. 144), uma concepção da vida como obra de arte, tarefa que exige contínuo trabalho sobre si mesmo.

Reflexão e criação não ocorrem espontaneamente, tampouco se pode acioná-las em um trabalho educativo quando o valor da experiência na aprendizagem é negligenciado, o que torna necessário àqueles que se propõem a trabalhar com a formação de professores a criação de condições para que as experiências de vida sejam acessadas e ressignificadas pelos participantes e sirvam de substância aos percursos pessoais de aprendizagem, do mesmo modo que o contexto formativo pode se constituir um espaço de vivência, convivência e construção de novas experiências.

O que foi mais importante para mim nessa disciplina foi como tudo fez sentido para mim. Todas as coisas, por mais variadas que fossem, tinham lugar no que eu acredito e no que eu quero desenvolver como artista e educadora. $O$ desenvolvimento pessoal proporcionado por essas propostas da professora teve uma relevância enorme para mim, e eu consegui relacionar o que eu quero, penso e sou com a minha posição na educação e na arte (mesmo que me mantenha aberta a mudanças). Todos esses elementos importantes por si mesmos conseguiram fazer parte de um todo que agora me estrutura. ${ }^{6}$

Tendo a experiência como célula mater da aprendizagem, ao longo da construção do sistema Cartografias de si, fomos criando os denominados atos cartográficos - exercícios que propõem práticas de si, dispositivos de subjetivação de natureza poético-pedagógica que visam acionar a reflexão crítica e a criação artística, didática e existencial dos participantes.

Deste modo, caderno de registros; relato autobiográfico, registro poético e criação didática são dispositivos centrais do referido sistema formativo introduzidos de forma gradual e articulada ao longo do desenvolvimento do trabalho, sem sacrifício da incerteza, da flexibilidade e da abertura necessárias ao desenvolvimento do processo formativo.

6 Trecho da reflexão final de J., estudante de licenciatura em Artes Visuais, escrita em 2017, no âmbito da disciplina de graduação Metodologia do Ensino das Artes Visuais I, da ECA/USP. 
Os resultados das proposições dos atos cartográficos, ou seja, as produções dos sujeitos participantes, aproximam-se, pois, da noção de diagrama, tal qual definida por Deleuze ao se referir ao conjunto da obra de Foucault:

[...] um diagrama é um mapa, ou melhor, uma superposição de mapas. E, de um diagrama a outro, novos mapas são traçados. Por isso, não existe diagrama que não comporte, ao lado de outros que conecta, pontos relativamente livres ou desligados, pontos de criatividade, de mutação, de resistência; e é deles, talvez, que será preciso partir para se compreender o conjunto (DELEUZE, 2013, p. 53).

Enquanto os dispositivos centrais anteriormente mencionados - caderno de registros; relato autobiográfico, registro poético e criação didática - são constantemente aperfeiçoados, antes, durante e após os trabalhos com os grupos, outros, com funções análogas a esses, são continuamente criados, de tal modo que o nosso próprio processo como propositores é profundamente marcado pela criação e reflexão, assim como ocorre com os participantes.

Os relatos autobiográficos são o disparador do processo formativo, por essa razão, colocaremos nossa atenção exclusivamente no lugar ocupado por esse dispositivo no âmbito do sistema Cartografias de si, buscando explicitar suas bases conceituais e experimentais.

A cartografia apresentada a seguir, texto e ensaio fotográfico, foi a primeira de três que compõem um percurso reflexivo-prático feito durante a disciplina Arte Experiência e Educação, Cartografias de Si [...] A proposta inicia-se pelo relato autobiográfico e adquire materialidade em uma linguagem à escolha do autor. Não sabia muito bem o que faria e tive a ideia de olhar as fotografias que estão guardadas em uma gaveta de mapoteca que foram feitas ao longo de quase quarenta anos: fotografias de viagem, fotografias profissionais feitas em estúdio e também timidos ensaios. O relato reflete essa 'visita à gaveta de fotos' e o desconforto que acompanhou esse primeiro momento, pois tive que lembrar e rever meu passado, vendo fotos de lugares e pessoas, inclusive o meu prório envelhecimento. Enquanto isso, buscava responder à pergunta: Qual é minha história ambiental? Como se tratava de uma relato autobiografico, o ato de rever e escolher as fotos se converteu em um balanço doloroso e revelador, mas que ao mesmo tempo retomou o caminho que in- conscientemente já havia sido apontado no projeto do doutorado: a fotografia. Passado esse primeiro impacto consegui identificar um momento muito significativo que poderia ser um tipo de índice da minha história ambiental: a viagem à cidade natal da minha família, Triunfo em Pernambuco. Essa viagem me marcou profundamente e tive a oportunidade de fazer muitas fotos. Foi feita em 2006 
(embora nem todas as fotos do ensaio sejam só dessa época). O resultado virou um marco na minha vida e se constituiu em uma narrativa visual bem pessoal. ${ }^{7}$

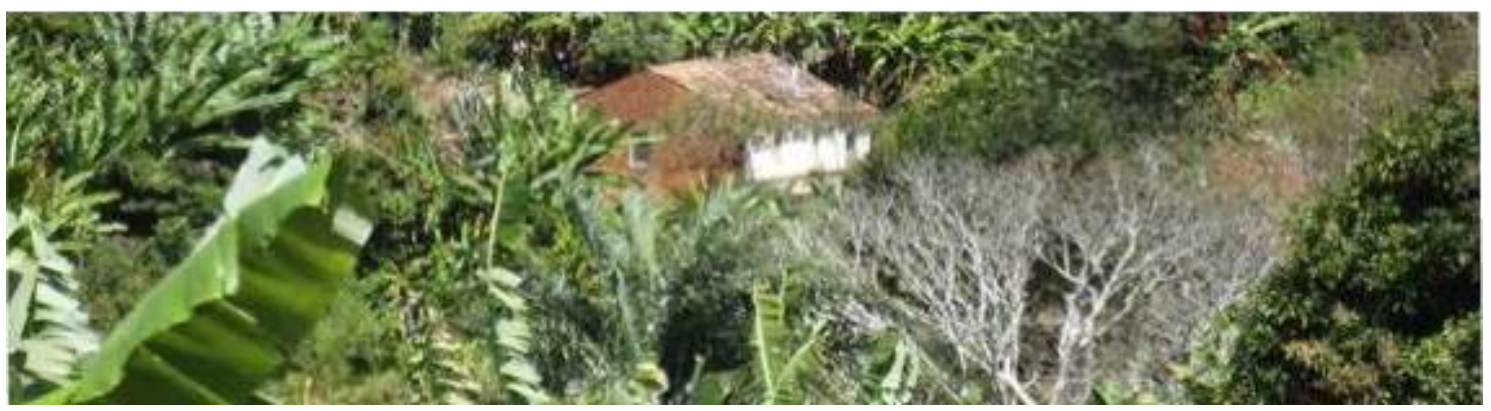

Figura 01. Foto da última cartografia feita por E. artista, professora e pesquisadora. Programa de Pós-Graduação em Artes Visuais da ECA/USP (2017).

\section{O relato autobiográfico como escrita de si}

Na seguinte passagem, Foucault refere-se à sua experiência pessoal com a escrita como um meio de transformação de si mesmo:

[...] meus livros são, para mim, experiências, em um sentido que gostaria o mais pleno possível. Uma experiência é qualquer coisa de que se sai transformado. Se eu tivesse de escrever um livro para comunicar o que já penso, antes de começar a escrevê-lo, não teria jamais a coragem de empreendê-lo. [...] Sou um experimentador no sentido em que escrevo para mudar a mim mesmo e não mais pensar na mesma coisa de antes (FOUCAULT, 2010, p. 289-290).

A escrita ocupava um lugar muito importante nas práticas em torno dos cuidados de si na cultura greco-romana, assumindo, conforme o filósofo, uma função etopoiéitica, ou seja, operava transformações nos modos de ser do indivíduo e, por conseguinte, na esfera da coletividade:

Nesses textos de Epícteto, a escrita aparece regularmente associada à "meditação", ao exercício do pensamento sobre ele mesmo que reativa o que ele sabe, toma presentes um princípio, uma regra ou um exemplo, reflete sobre eles, assimila-os, e assim se prepara para encarar o real. [...] a escrita constitui uma etapa essencial no processo para o qual tende toda a askêsis: ou seja, a elaboração dos discursos recebidos e reconhecidos como verdadeiros em princípios racionais de ação. Como elemento de

\footnotetext{
7 Foto e trecho da última cartografia feita por E. artista, professora e pesquisadora, realizada em 2017, no âmbito da disciplina de pós-graduação Arte, experiência e Educação, cartografias de si: percursos de formação e processos criativos de professores, do Programa de Pós-Graduação em Artes Visuais da ECA/USP.
} 
treinamento de si, a escrita tem, para utilizar uma expressão que se encontra em Plutarco, uma função etopoiéitica: ela é a operadora da transformação da verdade em êthos. Essa escrita etopoiéitica, tal como aparece em documentos dos séculos I e II, parece estar localizada no exterior das duas formas já conhecidas e utilizadas para outros fins: os hupomnêmata e a correspondência (FOUCAULT, 2004, p. 146-147).

Os atos cartográficos desenvolvidos no sistema Cartografias de si são práticas que favorecem a transformação dos sujeitos. São atos de dedicação e entrega de si para si, de si para o outro e do outro para si; atos que, possibilitando e incentivando o cuidado de si, promovem a colaboração e a implicação no grupo social. Portanto, além de éticos e poéticos, são atos políticos.

Das duas práticas de escrita de si destacadas por Foucault - os hupomnêmata e a correspondência - observamos uma proximidade da função ocupada pelos atos cartográficos, sobretudo, os relatos autobiográficos e os cadernos de registro, do sistema formativo Cartografias de si, com a função que os hupomnêmata exerciam na cultura greco-romana:

Os hupomnêmata, no sentido técnico, podiam ser livros de contabilidade, registros públicos, cadernetas individuais que serviam de lembrete. Sua utilização como livro de vida, guia de conduta parece ter se tornado comum a todo um público culto. Ali se anotavam citações, fragmentos de obras, exemplos e ações que foram testemunhadas ou cuja narrativa havia sido lida, reflexões ou pensamentos ouvidos ou que vieram à mente. Eles constituíam uma memória material das coisas lidas, ouvidas ou pensadas; assim, eram oferecidos como um tesouro acumulado para releitura e meditação posteriores (FOUCAULT, 2004, p. 147).

[...] trata-se não de buscar o indizível, não de revelar o oculto, não de dizer o não-dito, mas de captar, pelo contrário, o já dito; reunir o que se pode ouvir ou ler, e isso com uma finalidade que nada mais é que a constituição de si. [...] Tal é o objetivo dos hupomnêmata: fazer do recolhimento do logos fragmentário e transmitido pelo ensino, pela escuta ou pela leitura um meio para - estabelecimento de uma relação de si consigo mesmo tão adequada e perfeita quanto possível (FOUCAULT, 2004, p. 149).

Tal como ocorre com os hupomnêmata, que tinham por objetivo a "constituição de si" (FOUCAULT, 2004, p. 149), os relatos autobiográficos têm por objetivo possibilitar que os sujeitos desvendem o essencial sobre si mesmos, que, contudo, podem ter esquecido. 
Quase que automaticamente, me transportei para a adolescência e o relato veio "baixando, meio que pronto, como se estivesse escrito em algum lugar. ${ }^{8}$

Invariavelmente, é o relato autobiográfico a prática de si que aciona o sistema Cartografias de si e inicia o percurso de formação. A partir do convite para rememorar suas experiências formativas, o professor vasculha sua intimidade e encontra imagens soterradas na memória, ao mesmo tempo que intensifica o pensamento crítico para a vida vivida no presente e deflagra outras possibilidades para a sua existência.

[...] sou fruto das escolhas que fiz e continuo fazendo. É uma afirmação óbvia assinalada em teorias e compêndios de educação, filosofia e psicologia, porém, sua força está em se realizar para cada um, quer dizer, sua força existe quando o sujeito se dá conta da sua caminhada e se torna capaz de conectar esses caminhos com experiências e práticas que realiza. ${ }^{9}$

Relatar não é, pois, meramente descrever fatos, mas sim um exercício profundamente reflexivo e imaginativo, já que além de provocar o olhar para o já vivido, provoca deslocamentos.

Para o professor, rememorar não é somente constatar as contingências da vida ou da profissão, mas, sobretudo, ter a oportunidade de se deparar com a condição humana do seu ofício. Ao escrever o relato autobiográfico, localiza e ordena suas experiências, encontra relações entre elas e as decisões que tomou e percebe que uma intenção global dá a tônica da sua existência e alimenta o seu projeto de vida. Algo muito importante sobre si estava o tempo todo lá, mas só se tornaria acessível pela oportunidade de rememoração e narração da sua história de vida para outras pessoas.

Uma imagem que me vem sempre à mente desde as mais antigas lembranças é olhar a natureza como seu eu pudesse desvendar seus segredos através das suas formas. Talvez por isso fiz artes plásticas, virei fotografa após a faculdade e depois explorei as mídias eletrônicas que permitem retrabalhar essa observação, reinterpretar e simular novas visualidades. ${ }^{10}$

\footnotetext{
${ }^{8}$ Fragmento do relato autobiográfico de V., artista, professor e pesquisador, escrito em 2009, no âmbito da disciplina de pós-graduação Professores de arte: formação e prática educativa, do Programa de Pós-Graduação em Artes Visuais da ECA/USP.

${ }_{9}$ Fragmento do relato autobiográfico de V., artista, professor e pesquisador, escrito em 2009, no âmbito da disciplina de pós-graduação Professores de arte: formação e prática educativa, do Programa de Pós-Graduação em Artes Visuais da ECA/USP.

${ }^{10}$ Fragmento do relato autobiográfico de E., artista, professora e pesquisadora, escrito em 2017, no âmbito da disciplina de pós-graduação Arte, experiência e Educação, cartografias de si: percursos de formação e processos criativos de professores, do Programa de Pós-Graduação em Artes Visuais da ECA/USP.
} 


\section{A escuta das narrativas}

No âmbito do sistema Cartografias de si, os relatos pessoais são compartilhados entre os participantes do processo, tarefa que dura algumas semanas. Essa experiência de escuta e compartilhamento oferece a substância primária necessária ao trabalho individual e coletivo que será desenvolvido até o final do processo formativo, do mesmo modo que impulsiona e dá consistência ao grupo que está se iniciando.

Uma verdadeira comunidade de aprendizagem se constitui a partir deste momento, quando distintos sujeitos, em conexão e correlação narram suas histórias e ouvem as dos demais. A narração, a audição e o acolhimento das lembranças alegres e dolorosas da vida, vão, definitivamente ,estabelecendo um verdadeiro espaço de cuidado de si e dos outros.

[...] Os primeiros exercícios deram bases para o desenrolar de todo o processo de vivenciar estágios, compartilhar ideias e questões ao longo das aulas, já que envolviam diretamente investigações e interesses pessoais. Notar como tudo isso pode se entrelaçar, e não só minhas bagagens, mas as bagagens dos meus colegas de turma também foram se agregando e sendo contruídas juntas. Minha visão de escola, de professor, de educação, de ensino de arte, entre outras, foi repensada, construída, em alguns pontos fortalecida, à medida que as discussões em sala e leituras foram sendo feitas. A de professor principalmente, conto agora com a concepção de cooperador das ações exercidas em sala. ${ }^{11}$

Uma noção de processo inacabado, que se constitui na complexa relação entre tempo e espaço, preside as narrativas dos professores, evidenciando quão singular é cada existência.

Não há trajetórias absolutamente idênticas, pois inúmeros fatores objetivos e subjetivos concorrem para diferenciar uma existência de outra, porém, é possível encontrarmos elementos comuns nas trajetórias de envolvimento dos sujeitos com a arte e/ou a educação, bem como, fatores que favorecem ou não a confirmação desta afeição no decorrer da vida.

O ser humano carrega em si o universal, já dizia Ferrarotti (1988). Ao apropriar-se do sistema social, revela-o em cada uma das suas ações, comportamentos e representações, porém, aqueles que leem e/ou ouvem as narrativas precisam se esforçar

11 Trecho da reflexão final de JQ., estudante de licenciatura em Artes Visuais, escrita em 2017, no âmbito da disciplina de graduação Metodologia do Ensino das Artes Visuais I, da ECA/USP. 
para compreender o movimento singular de cada sujeito, do mesmo modo que devem ficar abertos para possíveis pontos de tangência entre as várias trajetórias de vida.

Isso significa que os relatos autobiográficos de educadores, de forma alguma, podem ser utilizados para confirmar determinadas teorias sobre a formação de professores e/ou se prestarem à construção de um modelo exemplar de educador. Eles nos ajudem a compreender aspectos gerais do contexto histórico e social de cada época, mas devem ser vistos como pontos de partida para a compreensão de que cada existência é única. Isso precisa ser considerado e respeitado nos diversos contextos de formação e de atuação de professores, marcados pela massificação, sob pena de as narrativas servirem para finalidades contrárias à concepção de subjetivação como processo inacabado e contínuo, uma tarefa do próprio sujeito.

Ainda que a questão central proposta aos educadores seja a rememoração das experiências significativas relacionadas à sua história de formação profissional, procuramos compreendê-la no âmbito do percurso de uma vida, abrangendo as etapas da existência humana: infância, adolescência e idade adulta, de onde emergem vivências primordiais no âmbito da família, da escola, da faculdade e do ambiente de trabalho, por exemplo, além de projeções para os tempos vindouros.

A memória resgata cenas, momentos, pessoas, situações e acontecimentos que tiveram uma importância maior para a trajetória formativa. Tais imagens ganham sentido quando compartilhadas com o grupo e submetidas ao exercício reflexivo coletivo, quando são sempre organizadas em cadeias significantes. Para tanto, uma atitude fenomenológica de todos os ouvintes é fundamental. Tal atitude pressupõe envolvimento com o sujeito que narra, ao mesmo tempo que possibilita o necessário distanciamento reflexivo.

Olhar, observar e captar visualmente é quase sempre, para mim, o primeiro passo no meu relacionamento com o mundo. É também o caminho para a percepção daquele algo mais sutil que está além da aparência mais imediata e que transparece no contato com a natureza e suas formas, texturas, luzes e cores. ${ }^{12}$

Invariavelmente, observamos um sentido global em cada trajetória, um sentido que se expressa na busca principal do sujeito. Para acessá-lo, precisamos ultrapassar os fatos narrados, dirigindo nossa atenção para os significados atribuídos e manifestados pelos

\footnotetext{
${ }^{12}$ Fragmento do relato autobiográfico de E., artista, professora e pesquisadora, escrito em 2017, no âmbito da disciplina de pós-graduação Arte, experiência e Educação, cartografias de si: percursos de formação e processos criativos de professores, do Programa de Pós-Graduação em Artes Visuais da ECA/USP.
} 
próprios narradores sobre os eventos que concorreram para o seu processo de subjetivação.

Nessa retrospectiva, uma foto surge na memória... Ela é ao mesmo tempo retrato e paisagem. Vou até a mapoteca e começo a procura-la, mas tudo começa a ficar confuso dentro de mim. São muitas fotos, negativos, slides! Centenas! Começo a entender porque ficaram assim adormecidas na gaveta por anos, estragando, sumindo... ${ }^{13}$

A noção de processo indica a especificidade de cada autobiografia, da mesma forma que aponta para a existência de traços comuns nas trajetórias dos professores. As palavras escritas explicitam a esfera da subjetividade, tornando as biografias irredutíveis a um modelo interpretativo.

A escuta atenta dos relatos procura elementos dissonantes que evidenciem as singularidades de cada trajetória, e assim, aos poucos, com a ajuda dos próprios participantes, o sentido da construção do projeto pessoal/profissional de cada pessoa vai se revelando para todo grupo.

[...] cheguei a um propósito de vida de curto-prazo com o qual me identifiquei: poder usar meus conhecimentos de design para desenvolver projetos de cunho social. Tracei etapas claras para conseguir chegar a esse objetivo. [.... O resultado que cheguei fez muito sentido para mim e hoje é algo que norteia a maioria das minhas escolhas e atitudes, inclusive na forma como estou conduzindo alguns debates [...]. ${ }^{14}$

Refletir sobre a própria formação exige do professor uma atitude deliberada e disponibilidade para pensar, rememorar e defrontar-se com as escolhas feitas e suas consequências, resgatando, confirmando, refutando ou recriando o seu projeto de ser professor. Não à toa, escrever uma narrativa autobiográfico implica aceitar o risco da dor, já que as escolhas feitas revelam possibilidades deixadas de lado e evidenciam ao sujeito seus erros, acertos e potencialidades.

Preciso relacionar, contar uma história, estabelecer uma narrativa coerente que estabeleça alguma lógica, algum nexo e me resgate desse mar de lembranças, pois sei com toda certeza que não gostei de ver todas essas fotos, assim, tão elas, tão juntas e de uma vez.

\footnotetext{
13 Idem.

${ }^{14}$ Trecho da reflexão final de C, estudante de Design, escrita em 2017, no âmbito da disciplina de graduação Metodologia do Ensino das Artes Visuais I, da ECA/USP.
} 
[...] o choque que me atinge dolorosamente talvez seja a idade: ver tantos retratos, mas nova, mais magra, sorridente, meiga, sonhadora, me choca talvez por "revelar aquilo que estava oculto". Ou seja, ela, a Fotografia, me pensa. A minha fototeca, portanto, é pensativa! E meu olho também e me conduz a um olhar pensar! Neste ponto acho que vou ter que me reconciliar com a fotografia. Vamos ver... e pensar... ${ }^{15}$

\section{Considerações finais}

Recordar o passado é recordar o que imaginamos para o futuro, é rever as bases de sustentação do nosso projeto de vida.

A experiência de elaboração e compartilhamento do seu relato autobiográfico propicia ao sujeito, por um lado, o conhecimento da dinâmica que ele imprime à própria existência, por outro, a descoberta de que pode criar outras possiblidades para a sua existência.

O elemento afetivo despertado na relação com os outros é crucial em um contexto formativo pautado no trabalho colaborativo, pois permite que as pessoas percebam o que há de comum entre elas, ao mesmo tempo que possibilita que expressem com liberdade suas singularidades.

Acreditamos que os atos cartográficos desenvolvidos no âmbito do sistema Cartografias de si, em especial, o relato autobiográfico, são práticas de si que integram, entre muitos outros elementos, o afeto.

Em uma época em que os professores são cada vez mais desvalorizados, essa perspectiva metodológica tem se revelado transformadora não apenas das práticas e concepções educativas dos sujeitos, senão também deles próprios.

\section{Referências}

BOSI, E. O Tempo Vivo da Memória: ensaios de psicologia social. São Paulo: Ateliê Editorial, 2003.

DAMATTA, R. Individualidade e liminaridade: considerações sobre os ritos de passagem e a modernidade. Mana, Rio de Janeiro, v. 6, n. 1, apr. 2000.

DELEUZE, G. Foucault. São Paulo: Brasiliense, 2013.

\footnotetext{
${ }^{15}$ Fragmento do relato autobiográfico de E., artista, professora e pesquisadora, escrito em 2017, no âmbito da disciplina de pós-graduação Arte, experiência e Educação, cartografias de si: percursos de formação e processos criativos de professores, do Programa de Pós-Graduação em Artes Visuais da ECA/USP.
} 
FERRAROTTI, F. Sobre a autonomia do método autobiográfico. In: FINGER, M.; NÓVOA, A. (org.). O método (auto)biográfico e a formação. Cadernos de Formação 1. Lisboa: Ministério da Saúde, 1988. p.19-34.

FOUCAULT, M. Ética, sexualidade, política: Ditos \& escritos V. Rio de Janeiro: Forense Universitária, 2004.

Repensar a política: Ditos \& escritos VI. Rio de Janeiro: Forense Universitária, 2010.

MATTAR, S. Aprender a ouvir o som das águas: o projeto poético-pedagógico do professor de arte. Dissertação (Mestrado em Artes Visuais) - Faculdade de Educação da Universidade de São Paulo, FEUSP, 2002.

Descobrir as texturas da essência da terra: formação inicial e práxis criadora do professor de arte. 2007. 299p. Tese (Doutorado em Educação) - Faculdade de Educação da Universidade de São Paulo - FEUSP, São Paulo, 2007.

Sobre arte e educação: entre a oficina artesanal e a sala de aula. Campinas: Papirus, 2010.

MATTAR, S. Memória e reflexão: a biografia como metodologia de investigação e instrumento de (auto) formação de professores de arte. Disponível em: (http://www.anpap.org.br/anais/2009/pdf/ceav/sumaya mattar moraes.pdf>.

MATTAR, S. Práticas de registro e processo de ensino-aprendizagem da arte. In: Cadernos de Registro Macu. São Paulo: Teatro Escola Macunaíma, 2017a, p. 6- 15. Disponível em: $<$ http://www.macunaima.com.br/cadernos/caderno 10/caderno 10 dossie01.pdf $>$.

- O ato cartográfico na docência da arte: instaurando estados criativos de experimentação. ENCONTRO NACIONAL DA ANPAP, 26, Anais... Anpap: Campinas, 2017b. Disponível em: <http://www.anpap.org.br>.

Cartografias de si como processo (auto) formativo de educadores: apontamentos de viagem. In: ALVES, C.J.G.; SOUZA, M.I.P.O.; OLIVEIRA, R.A. (Org.). Cartografias da formação e da ação docente nas artes: reflexões acerca da experiência. Londrina: PARFOR/UEL, 2017c.

MATTAR, S.; ROIPHE, A. Arte e educação: ressonâncias e repercussões. São Paulo: 
ECA/USP,

2016.

Disponível

em:

<http://artenaescola.org.br/uploads/livros/ebook/Arte e educacao ressonancias e repe

rcussoes.pdf $>$.

i Docente do Departamento de Artes Visuais e do Programa de Pós-Graduação em Artes Visuais da ECA/USP. Licenciou-se em Artes Plásticas pela Universidade Federal de Uberlândia (UFU), tendo realizado mestrado e doutorado na FE-USP. Desenvolve projetos de pesquisa e projetos de formação de professores de arte voltados à criação didática e coordena projetos de ação educativa com abordagem interdisciplinar envolvendo crianças do ensino fundamental, jovens, adolescentes e adultos. É líder do GMEPAE - Grupo Multidisciplinar de Estudo e Pesquisa em Arte e Educação, da ECA/USP, que congrega pesquisadores, estudantes e educadores de diversos campos de conhecimento. Entre outras publicações, é autora do livro "Sobre arte e educação: entre a oficina artesanal e a sala de aula" (Ed. Papirus, 2010) e do documentário: "Shoko: expressão do cosmos" (2006), sobre a vida e a obra da ceramista Shoko Suzuki, de quem foi aluna.

Como citar esse artigo:

MATTAR, Sumaya. O lugar do relato autobiográfico no sistema formativo cartografias de si. Revista Digital do LAV, Santa Maria: UFSM, v. 11, n. 2, p. 259-273, mai./ago. 2018. 